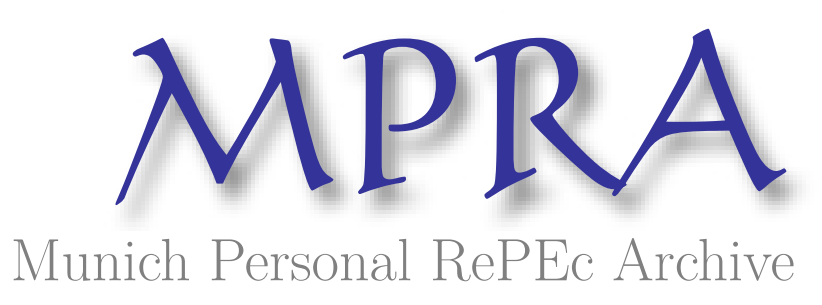

\title{
Coping with Externalities in Tourism - A Dynamic Optimal Taxation Approach
}

Schubert, Stefan Franz

Free University of Bozen-Bolzano

July 2009

Online at https://mpra.ub.uni-muenchen.de/16736/

MPRA Paper No. 16736, posted 11 Aug 2009 05:42 UTC 


\title{
Coping with Externalities in Tourism - A Dynamic Optimal Taxation Approach
}

\author{
Stefan F. Schubert* \\ Competence Centre in Tourism Management and Tourism Economics (TOMTE) \\ Free University of Bozen-Bolzano, Italy
}

June 2009

*Mail: Free University of Bozen-Bolzano, School of Economics and Management, Piazza Università 1, I-39100 Bolzano, E-mail: StefanFranz.Schubert@unibz.it 
The paper studies optimal taxation (subvention) when tourism is associated with "multiple externalities", using a simple dynamic model of a small open economy, which is completely specialized in the production of tourism services and populated by a large number of intertemporally optimizing agents. Depending on the volume of tourism production, the externality can be either positive or negative. We show that the first best optimum, achieved by a central planner, recognizing the externality, can be replicated in a decentralized economy by using a time-varying tax rate. This ensures that (i) the steady state of the first best optimum is reached and that (ii) the speed of convergence to steady state is socially optimal.

Keywords: tourism demand, externalities, dynamic optimal taxation

JEL classification: F 41, H 21, H 23, R 13 


\section{Introduction}

One of the impacts of globalization has been the growth in tourism and the mobility of capital. Of course, growth in tourism is associated with increasing numbers of tourists visiting a country or a region, contributing to the local economy's income. In turn, the needs of increasing numbers of guests for accommodation and an appropriate infrastructure will normally be met by construction of new hotels and improvements of local infrastructure. As numbers of visitors grow, a lot of other facilities aimed to please tourists and to give them an impressive stay will be created, too. Thus, via investments capacities of existing tourism services will be increased or new supplies will be built. Of course, such investments have to be financed. Thanks to the increased mobility of capital, international borrowing makes financing easier and facilitates growth of the tourism industry. It is obvious that increasing capacities of tourism facilities and growing numbers of visitors have various effects, both economic and non-economic, on the host country or region. An improved infrastructure, different culture and life-styles of foreign visitors can generate positive sediments to local people, but massive streams of tourists can turn local residents' life into a nightmare (Chao et al. (2004)). Moreover, tourism can lead to a degradation of nature, which in turn lowers quality of life both for residents and tourists. Thus, tourism and nature (the environment) can be in conflict, in coexistence or in symbiosis, as Budowski (1976) categorizes ins his classic article.

It is often difficult to assess and to handle the numerous side-effects associated with tourism, particularly the non-economic ones, as no markets for them exist. They constitute externalities, as they are benefits or costs that tourists or firms confer on others without receiving compensation. Because of these side effects that markets do not take into account, externalities can lead to individual decisions that are not optimal for a society as a whole, and these externalities can be quite huge. To improve welfare of residents, it is therefore important to implement appropriate policies to deal with externalities. This paper addresses the issue of optimal policy in a growing tourism economy to cope with externalities caused by tourism.

The list of externalities associated with tourism is long. Externalities which negatively impinge on residents' welfare are, for example: crowding and congestion of roads, public transportation and cities, and thus conflicts between tourists and residents in using infrastructure, noise, litter, property destruction, pollution, increased water consumption per head, $\mathrm{CO}_{2}$ emissions, changes in community appearance, overbuilding, changes in the landscape and views, degradation of nature, e.g. caused by saturation of 
construction and development projects, depletion of wildlife, damage to cultural resources, land use loss, increased urbanization, and increased crime rate. A concrete case is reported in Aguiló et al. (2005), stating that on the balearic islands, the level of groundwater fell by 90 meters between 1975 and 1999, and that the production of of domestic waste doubles that of the national average. Barros (2006) detects inefficiencies in the Portuguese hotel industry, caused by economies of scope and (external) economies of scale, beside other factors as bad management. On the other hand, tourism can have beneficial impacts, enhancing residents' living. Examples for such positive externalities are: more and better leisure facilities, more beaches designated as parks, ${ }^{1}$ greater recognition of the importance of saving historical buildings, development of infrastructure respectively better infrastructure, pollution control, clean beaches, cultural exchange, giving residents a better understanding about the world, increasing wealth of residents, better public health system, and so on. ${ }^{2}$ It is thus evident that tourism generally disrupts social, cultural and environmental local systems, and that non-economic impacts of tourism often tend to be negative as a whole, whereas economic side effects are normally perceived as positive (see Figini et al. (2007)).

As the numerous examples reveal, tourism is associated with both positive and negative externalities at the same time. According to Candela et al. (2008), they can be defined as "multiple externalities" or intersecting externalities in the sense that the overall externality inherent with tourism can change from positive to negative depending on the level of tourism, when, e. g., the costs of congestion and degradation of nature overcome the benefits of tourism. By their very nature, externalities are not recognized properly when tourism firms decide about their hotel capacities, the creation of leisure facilities, and so on. Thus, in general the tourism service market, on which the price of tourism services equilibrates supply and demand, will not operate optimally from a social point of view. To correct for the market failure such "multiple externalities" produce, some form of market intervention is necessary. Policy can use its instruments to improve the overall performance of the economic system in direction of what is socially optimal.

It is well-known from the economics literature that externalities can be internalized by using taxes (Pigouvian tax) or subsidies. ${ }^{3}$ It is therefore straightforward to correct for the externalities associated with tourism by imposing a tourism tax. ${ }^{4}$ In fact, as Palmer and Riera (2003) and Aguiló et al. (2005) report, on the balearic islands, which suffer from negative effects of mass tourism, an "ecotax" (tourism 
tax) with a median rate of one Euro per day and head was introduced. (However, in reality it turned out that this tax was purely and simply an instrument designed to generate revenue.)

Historically, tourism services have always been subject to taxes. An extensive study on tourism taxation was done by Forsyth and Dwyer (2002), showing evidence that tourism is relatively heavily taxed and that the rates of taxation are increasing. A comprehensive tourism tax typology is provided by Gooroochurn and Sinclair (2005). According to them, more than 40 different types of taxes applied to the tourism industry in both developed and developing countries can be identified, most of them payable by the consumer, i.e. the tourist. ${ }^{5}$ Examples of tourism taxes are: entry/exit tax, bed night tax, occupancy tax, accommodation tax, service tax, eco-tourism tax, visa and travel permits, air passenger duties, to name only a few.

The objective of tourism taxes is twofold: to generate revenue and, as already indicated, to correct for market failures. While taxation of tourism can be an important source of government revenue, deserving an analysis on its own, we shall focus on the second purpose of taxation, the internalization of external effects aiming at achieving a socially desirable outcome. This is an important issue, because if such an intervention in markets is properly done, overall welfare in the host country or region improves, increasing thus residents' quality of life substantially.

Of course, the analysis of optimal tourism taxation is not completely new. Recently, Pintassilgo and Silva (2007) and Candela et al. (2007) derived an optimal tourism tax in a static partial equilibrium framework. Because of the presence of intersecting externalities, the social optimum may be replicated by using a tax or a subsidy (in case of a positive overall externality). While the use of a static partial equilibrium framework has its merits, it clearly neglects repercussions of tourism and of taxation across different economic entities and across time. Piga (2003) uses a dynamic partial equilibrium model to explicitly link tourism, its use of natural resources and policy intervention. He derives optimal taxation rules for different strategic settings. Cerina (2007) analyzes dynamic optimal taxation with respect to environmental sustainability, using a small open economy model without capital formation and foreign borrowing. Because of the specific functional forms assumed, the optimal tourism tax is time-invariant. A dynamic model of a growing small open economy completely specialized in tourism production is developed by Gómez et al. (2008), focussing on tourism taxation as an instrument to internalize environmental impacts and to increase long-run welfare along a balanced growth path. ${ }^{6}$ 
This paper provides an important contribution to the analysis of optimal tourism taxation, as it extends the models used in the literature so far in several ways. First, we consider intersecting externalities in a general equilibrium framework, taking account of all repercussions. As we will see, the optimal policy to handle intersecting externalities and to replicate the social (first-best) optimum can be a tax or a subsidy, depending on the sign of the "multiple externality". Second, we explicitly introduce capital accumulation, necessary to increase the production potential of tourism services. We thus add an intertemporal dimension to the problem of internalizing externalities. Third, in contrast to previous work ${ }^{7}$, we allow for international borrowing (lending) to finance investment of domestic tourism firms and domestic residents' consumption. This is an important extension, as, referring to international capital mobility, it realistically relaxes a country's or region's resource constraint. Thus, investments in tourism are not constrained period by period by earnings from tourism. ${ }^{8}$ Rather, an intertemporal budget constraint has to be met. Fourth, we do not restrict our attention on the economy's steady state (or balanced growth path), an analysis which has its own merits, but also pay close attention on the transitional dynamics. ${ }^{9}$

To investigate intersecting externalities and optimal corrective policies in a tourism country or region in which tourism is growing towards its steady state level, we develop a simple model of a small open economy, which is completely specialized in the production of tourism services (island model). ${ }^{10} \mathrm{Al}-$ though tourism services can be taxed or subsidized on the side of producers (tourism firms) or consumers (tourists), according to the empirical findings in Gooroochurn and Sinclair (2005) we prefer modeling the policy on the consumer (tourist) side (see also Forsyth and Dwyer (2002)). We explicitly allow for foreign borrowing or lending and incorporate the economy's current account. We impose a solvency condition, ruling out Ponzi schemes of unsustainable development. We would like to stress that this kind of open economy framework refers also to a region within a country and may fit particularly well to a region's economic environment. For analytical purposes and as a starting point, we focus on the case that overall labor is supplied in a fixed quantity. After analyzing the first-best social optimum, achieved in the centrally planned economy, we show that the equilibrium in the decentralized economy is suboptimal. Using the method described in Turnovsky (1997), we will replicate the fist-best optimum in a growing tourism economy by a time-variant policy, that is by an increasing tax/falling subsidy on/to tourism, depending on the sign of the "multiple externality", and in particular cases by a policy switch from subsidizing to taxing tourism. 
The rest of the paper is structured as follows. The following section sets up the model of a small island economy and describes the economic framework. We then turn to the discussion of the macroeconomic equilibrium in the centrally planned economy. After that, the equilibrium in the decentralized economy is analyzed. We then replicate the first-best optimum in the decentralized economy by introducing a dynamic optimal tourism tax or subsidy. Finally, our main findings are summarized.

\section{The analytical framework}

The small open economy comprises a large number of identical households and competitive firms, which are completely specialized in the production of tourism services. ${ }^{11}$ Households supply a fixed amount of labor, $l_{i}=\bar{l}_{i}$, and consume an imported good. Firms produce tourism services, $y_{i}$, using capital, $k_{i}$, and labor, $l_{i}$, as factor inputs, according to a standard neoclassical technology. The imported good can be used for consumption, $x_{i}$, and investment, $I_{i}$, including installation cost, resulting in the investment cost function $C\left(I_{i}\right)$. Both households and firms shall be represented by a representative household and a representative firm, respectively. The economy is small in the world financial markets, taking the world interest rate $r$ as given. ${ }^{12}$ However, tourism services produced in the economy are different from tourism services supplied elsewhere. Therefore, aggregate foreign demand $Z$ for domestically produced tourism services is a decreasing function of the relative price of domestically produced tourism services in terms of the import good, $p$, i. e., the terms of trade of the domestic economy. ${ }^{13}$

$$
Z=Z(p), \quad Z^{\prime}<0
$$

Without loss of generality we can consolidate households and firms into a representative consumerproducer, called representative agent. We shall assume that the the number of agents in the economy remains constant over time and is given exogenously as $N$. The representative agent, denoted by subscript $i$, accumulates traded foreign bonds (assets), $b_{i}$, denoted in terms of the imported good, that pay the exogenously given world interest rate, $r$. The agent's flow resource constraint in terms of the foreign (imported) good is thus given by

$$
\dot{b}_{i}=p F_{i}\left(k_{i}\right)-x_{i}-C\left(I_{i}\right)+r b_{i}
$$


where $y_{i}=F_{i}\left(k_{i}\right)$ denotes the production function for tourism services, which shows the neoclassical standard properties $F_{i}^{\prime}>0, F_{i}^{\prime \prime}<0,{ }^{14}$ where for ease of notation we dropped constant labor $l_{i}$ as an argument of $F_{i}$. Since the domestic economy is completely specialized in tourism production, both the consumption good and physical capital must be imported from abroad. Capital formation (investment) is associated with convex adjustment costs of the Hayashi (1982) type. $C\left(I_{i}\right)$ denotes the investment cost function in terms of the foreign good, that is, total expenditure for capital formation (new capital plus installation cost), and has the properties $C^{\prime} \geq 0, C^{\prime \prime}>0, C^{\prime}(0)=1$. The agent receives interest income $r b_{i}$ from his holdings of foreign assets. Assuming away depreciation, the change in the capital stock and investment are related by

$$
\dot{k}_{i}=I_{i}
$$

A key feature of the model is that aggregate tourism production is associated with an intersecting externality, affecting the agent's level of utility. For the sake of simplicity, we assume that the agent's utility function is additively separable in the consumption good and the externality,

$$
u_{i}\left(x_{i}, \frac{Z}{N}\right) \equiv U_{i}\left(x_{i}\right)+V_{i}\left(\frac{Z}{N}\right)
$$

For analytical convenience, we model the externality being dependent on the level of tourism demand (which in equilibrium equals tourism production) relative to the number $N$ of domestic residents. Because we treat the number of agents $N$ as constant, there is no difference to model the externality in absolute terms rather than in relative terms. ${ }^{15}$ The instantaneous sub-utility function $U_{i}$ is assumed to be concave, i. e., $U_{i}^{\prime}>0, U_{i}^{\prime \prime}<0$. The sub-utility function $V_{i}$ containing the multiple externality is assumed to be concave, too, i. e., $V_{i}^{\prime \prime}<0$; however, similar to Chao et al. (2004), and Candela et al. (2008), for small levels of tourism $V_{i}^{\prime}>0$, i. e., tourism gives rise to a positive externality, enhancing the agent's wellbeing, whereas for high levels of tourism $V_{i}^{\prime}<0$, that is, tourism is associated with a negative externality, reducing the agent's welfare. ${ }^{16}$ The representative agent's intertemporal utility function is given as

$$
W_{i} \equiv \int_{0}^{\infty}\left[U_{i}\left(x_{i}\right)+V_{i}\left(\frac{Z}{N}\right)\right] e^{-\beta t} d t
$$

where $\beta$ is the rate of consumer time preference, taken to be constant. 
It is important that from the point of view of an individual agent, aggregate tourism demand represents an externality, as the agent is too small to influence the market for tourism services. Moreover, he takes the relative price of tourism services, $p$, as given. This price is determined in macroeconomic equilibrium by the requirement that the competitive market for domestically produced tourism services is to be continuously cleared, that is

$$
N F_{i}\left(k_{i}\right)=Z(p)
$$

where $N F_{i}\left(k_{i}\right)$ is aggregate tourism production. ${ }^{17}$

As a benchmark, we first describe the socially optimal equilibrium emerging in a centrally planned economy.

\section{Equilibrium in the centrally planned economy}

The central planner, in deciding about the representative agent's rates of consumption, bond and capital accumulation, to maximize welfare $W_{i}$, see (2), subject to the constraints (1) and the initial conditions $k_{i}(0)=k_{i 0}$ and $b_{i}(0)=b_{i 0}$, takes the externality into account by recognizing the equality between aggregate tourism demand and aggregate production, equation (3). ${ }^{18}$ The present value Hamiltonian for the central planner's optimization problem is given by

$$
H \equiv U_{i}\left(x_{i}\right)+V_{i}\left(F_{i}\left(k_{i}\right)\right)+\lambda\left[p F_{i}\left(k_{i}\right)-x_{i}-C\left(I_{i}\right)+r b_{i}\right]+\gamma I_{i}
$$

where $\lambda$ is the shadow value or the marginal utility of wealth in the form of traded foreign bonds, and $\gamma$ measures the shadow value of capital. Performing the optimization gives rise to the following optimality conditions:

$$
\begin{gathered}
U_{i}^{\prime}\left(x_{i}^{*}\right)=\lambda^{*} \\
C^{\prime}\left(I_{i}^{*}\right)=\frac{\gamma^{*}}{\lambda^{*}} \equiv q^{*} \\
\beta-\frac{\dot{\lambda}^{*}}{\lambda^{*}}=r \\
\frac{V_{i}^{\prime} F_{i}^{\prime}\left(k_{i}^{*}\right)}{q^{*} \lambda^{*}}+\frac{p^{*} F_{i}^{\prime}\left(k_{i}^{*}\right)}{q^{*}}+\frac{\dot{q}^{*}}{q^{*}}=r
\end{gathered}
$$


together with the transversality conditions

$$
\lim _{t \rightarrow \infty} \lambda^{*} b_{i}^{*} e^{-\beta t}=\lim _{t \rightarrow \infty} \gamma^{*} k_{i}^{*} e^{-\beta t}=\lim _{t \rightarrow \infty} \lambda^{*} q^{*} k_{i}^{*} e^{-\beta t}=0
$$

where an asterisk denotes equilibrium in the centrally planned economy. Equation (4a) equates the marginal utility of consumption of the imported good to the marginal utility of wealth in the form of foreign bonds. Equation (4b) gives rise to a Tobin $q$ theory of investment. It equates the marginal cost of investment (new capital) to its market price, both expressed in terms of the foreign good. ${ }^{19}$ Equations (4c) and (4d) are dynamic no-arbitrage conditions. The former equates the rate of return on consumption to the rate of return on bonds, i. e., the interest rate. To obtain an interior solution, we require $\beta=r$, which leads to the zero-root property (see Sen (1994)), implying a time-constant marginal utility of wealth,

$\lambda^{*}=\bar{\lambda}^{*}$. Equation (4d) equates the rate of return on capital invested in the tourism sector, consisting of a social dividend yield $V_{i}^{\prime} F_{i}^{\prime} /\left(q^{*} \lambda^{*}\right)+p^{*} F_{i}^{\prime} / q^{*}$ and a capital gain $\dot{q}^{*} / q^{*}$, to the exogenous world interest rate. The social dividend yield comprises two terms: the marginal value product of capital relative to its market price, and the marginal externality of capital, $V_{i}^{\prime} F_{i}^{\prime}$, expressed in terms of utility, being positive or negative, depending on the level of tourism, relative to the value of capital in terms of utility, $q^{*} \lambda^{*}$.

\section{Centralized macroeconomic equilibrium}

The macroeconomic equilibrium of this intertemporal general equilibrium model is defined to be a situation in which all the planned supply and demand functions are derived from optimization behavior, the economy is continually in equilibrium, and all anticipated variables are correctly forecasted. We will call this concept a "perfect foresight equilibrium". ${ }^{20}$ In particular, macroeconomic equilibrium requires the market for domestically produced tourism services to be continuously cleared. This market clearance, see equation (3), is maintained by proper adjustments of the relative price of tourism services. Together with the consumption and investment optimality conditions (4a) and (4b) we get

$$
\begin{gathered}
x_{i}^{*}=x\left(\bar{\lambda}^{*}\right), \quad \frac{d x_{i}^{*}}{d \bar{\lambda}^{*}}=\frac{1}{U_{i}^{\prime \prime}}<0 \\
I_{i}^{*}=I\left(q^{*}\right), \quad \frac{d I_{i}^{*}}{d q^{*}}=\frac{1}{C^{\prime \prime}}>0
\end{gathered}
$$




$$
p^{*}=p\left(k_{i}^{*}\right), \quad p^{\prime}=\frac{N F_{i}^{\prime}}{Z^{\prime}}<0
$$

The interpretation is straightforward: An increase in the marginal utility of wealth leads to an increase in savings and therefore a decrease in consumption expenditure. An increase in the market price of installed capital encourages capital formation and thus investment. A higher capital stock in turn increases production of tourism services and calls, other things equal, for a lower relative price to clear the market for tourism services.

Denoting steady-state values with tildes, the linearized dynamics for the centrally planned economy's capital stock and the the market price of installed capital follows from (1b) together with (5b), (5c), and (4d) and is given by

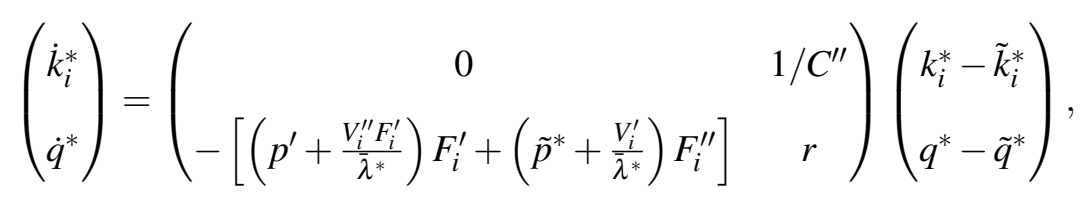

where all derivatives are calculated at steady-state. The characteristic equation is

$$
\phi\left(\mu^{*}\right)=\left(\mu^{*}\right)^{2}-r \mu^{*}+\frac{1}{C^{\prime \prime}}\left[\left(p^{\prime}+\frac{V_{i}^{\prime \prime} F_{i}^{\prime}}{\bar{\lambda}^{*}}\right) F_{i}^{\prime}+\left(\tilde{p}^{*}+\frac{V_{i}^{\prime}}{\bar{\lambda}^{*}}\right) F_{i}^{\prime \prime}\right]=0
$$

This determines the two eigenvalues $\mu_{1}^{*}<0$ and $\mu_{2}^{*}>0$. They have different signs because the the constant term in (7) is negative. ${ }^{21}$ The stable solution for the capital stock, $k_{i}^{*}$, and its market price, $q^{*}$, is:

$$
\begin{gathered}
k_{i}^{*}(t)-\tilde{k}_{i}^{*}=\left(k_{i 0}-\tilde{k}_{i}^{*}\right) e^{\mu_{1}^{*} t} \\
q^{*}(t)-\tilde{q}^{*}=\mu_{1} C^{\prime \prime}\left(k_{i 0}-\tilde{k}_{i}^{*}\right) e^{\mu_{1}^{*} t} .
\end{gathered}
$$

As can be seen from (8), the stable saddle-path is $q(t)^{*}-\tilde{q}^{*}=\mu_{1} C^{\prime \prime}\left(k_{i}^{*}(t)-\tilde{k}_{i}^{*}\right)$, which is a negatively sloped line in $\left(k^{*}, q^{*}\right)$-space.

Equation (1a) represents the current account, comprising the trade balance $F_{i}^{*}-x_{i}^{*}-C\left(I_{i}^{*}\right)$ and net interest income $r b_{i}^{*}$. The current account dynamics (external dynamics) follow from inserting equations (5a), (5b) and (5c) into (1a), linearizing and using the stable solutions for $k_{i}^{*}$ and $q^{*}(8)$, as

$$
\dot{b}_{i}^{*}=\Omega_{1}^{*}\left(k_{i}^{*}-\tilde{k}_{i}^{*}\right)+r\left(b_{i}^{*}-\tilde{b}_{i}^{*}\right)
$$


where

$$
\Omega_{1}^{*} \equiv p^{\prime} \tilde{F}_{i}^{*}+\tilde{p}^{*} F_{i}^{\prime}-\mu_{1}^{*}=\left(\frac{1}{\eta}+1\right) \tilde{p}^{*} F_{i}^{\prime}-\mu_{1}^{*}
$$

$\eta$ denotes the price elasticity of tourism demand. ${ }^{22}$ A sufficient condition for $\Omega_{1}^{*}>0$ is $|\eta|>1$, as empirical evidence suggests. ${ }^{23} \Omega_{1}^{*}$ captures the influence of capital on the balance of trade and services along a stable adjustment path. First, an increase in $k_{i}^{*}$ lowers the relative price to clear the tourism service market via increased demand $Z^{*}$. If that demand is price elastic, tourism services measured in terms of imports, $p^{*} Z^{*}$, increase, improving thus the current account. Second, an increase in $k_{i}^{*}$ lowers investment along the stable adjustment path, reducing thus investment imports and contributing positively to the country's current account, too.

In appendix A.1, we show that the stable solution for the economy's (per capita) net foreign asset position is

$$
b_{i}^{*}(t)-\tilde{b}_{i}^{*}=\frac{\Omega_{1}^{*}}{\mu_{1}^{*}-r}\left(k_{i}^{*}(t)-\tilde{k}_{i}^{*}\right)
$$

Setting $t=0$ in (10) yields the economy's intertemporal budget constraint which ensures that the economy remains intertemporally solvent.

Assuming that the economy's initial value of capital $k_{i 0}$ is below steady state, the economy grows along the stable saddle-path towards the socially optimal long-run equilibrium, $\tilde{k}_{i}^{*}$. The transitional dynamics are characterized by positive investment expenditures, as the market price of capital is above unity, providing thus investment incentives, and a decumulation of net foreign assets, as the centrally planned economy runs a current account deficit. In other words, it's growth is financed by either running down assets or by accumulating debt, i. e., by foreign borrowing.

\section{Steady state in centralized economy}

The economy's steady-state equilibrium is reached when $\dot{k}_{i}^{*}=\dot{q}^{*}=\dot{b}_{i}^{*}=0$. Hence, we get the steadystate relationships

$$
\begin{gathered}
U_{i}^{\prime}\left(\tilde{x}_{i}^{*}\right)=\bar{\lambda}^{*} \\
\tilde{q}^{*}=1 ; \quad \tilde{I}_{i}^{*}=0 \\
N F_{i}\left(\tilde{k}_{i}^{*}\right)=Z\left(\tilde{p}^{*}\right)
\end{gathered}
$$




$$
\begin{gathered}
\tilde{p}^{*} F_{i}^{\prime}\left(\tilde{k}_{i}^{*}\right)+\frac{V_{i}^{\prime}\left(F_{i}\left(\tilde{k}_{i}^{*}\right)\right)}{\bar{\lambda}^{*}} F_{i}^{\prime}\left(\tilde{k}_{i}^{*}\right)=r \\
\tilde{p}^{*} F_{i}\left(\tilde{k}_{i}^{*}\right)-\tilde{x}_{i}^{*}+r \tilde{b}_{i}^{*}=0 \\
b_{i 0}-\tilde{b}_{i}^{*}=\frac{\Omega_{1}^{*}}{\mu_{1}^{*}-r}\left(k_{i 0}-\tilde{k}_{i}^{*}\right)
\end{gathered}
$$

Several aspects of this equilibrium merit comment. First, because of the constant marginal utility of wealth, there is perfect consumption smoothing, as equation (11a) indicates. This is a standard result and due to the fixity of labor supply, see Turnovsky (2000, ch. 8 ), and the agent's additively separable utility function. Second, the steady-state market price of installed capital equals unity (equation (11b)), implying zero investment expenditures. Third, equations (11c) and (11d) jointly determine the longrun market clearing relative price of tourism services and the socially optimal long-run capital stock by requiring tourism market clearance and equality between the rates of the social return on capital and traded bonds. Fourth, equation (11e) is the steady-state zero current account, stating that in steady state consumption expenditures (imports) $\tilde{x}_{i}^{*}$ equal income in terms of the import good, comprising income from tourism service production $\tilde{p}^{*} \tilde{F}_{i}^{*}$ and net interest income $r \tilde{b}_{i}^{*}$. If the country is a net debtor $\left(\tilde{b}_{i}^{*}<0\right)$, consumption of the import good has to fall short of income from tourism service production to be able to service the debt. Finally, (11f) links the long-run capital stock to steady-state net foreign assets $b_{i}^{*}$ via the economy's solvency condition, and shows that the steady-state is dependent on the historically given initial levels of capital and bonds.

Note that by taking the externality into account, the dynamic adjustment paths and the steady state chosen by the central planner maximize the representative agent's welfare. Thus, the equilibrium in the centrally planned economy is the first-best optimum.

\section{Equilibrium in the decentralized economy}

We now turn to the representative agent operating in a decentralized economy. The objective of the agent is to maximize his intertemporal utility function (2), subject to the historically given initial stocks of capital $k_{i}(0)=k_{i 0}$ and traded bonds $b_{i}(0)=b_{i 0}$, the constraint (1b), and his flow budget constraint

$$
\dot{b}_{i}=p_{S} F_{i}\left(k_{i}\right)-x_{i}-C\left(I_{i}\right)+T_{i}+r b_{i}
$$


$T_{i}$ denote lump-sum payments from the government (if $T_{i}<0$, the agent has to pay a lump-sum tax), and $p_{S}$ is the supply price of tourism services the producer receives. In making his decisions, the agent takes the aggregate level of tourism services $Z$ and the supply price $p_{S}$ as given. The first order conditions of the agent's optimization problem are as in equations (4), with one fundamental difference: Because the agent does not care about the externality, the no-arbitrage condition for capital becomes

$$
\frac{p_{S} F_{i}^{\prime}\left(k_{i}\right)}{q}+\frac{\dot{q}}{q}=r
$$

requiring that the private dividend yield $p_{S} F_{i}^{\prime} / q$ and the capital gain $\dot{q} / q$ have to equal to the interest rate.

The government taxes tourism with a specific tax $\tau$, expressed in terms of the import good, payed by tourists. ${ }^{24}$ Hence, the tax drives a wedge between the demand price $p_{D}$ consumers of tourism services have to pay and the supply price $p_{S}$ producers receive:

$$
p_{D}=p_{S}+\tau
$$

Recognizing that tourism service demand depends on the demand price, i. e., $Z\left(p_{D}\right)$, the government's total tax revenues are $\tau Z\left(p_{D}\right)$. Because we concentrate on the internalization of externalities, we assume that the government runs a balanced budget by returning tax revenues to domestic residents in a lumpsum fashion. ${ }^{25}$ Hence, the government's budget constraint is

$$
\tau Z\left(p_{D}\right)=N T_{i}
$$

Taking taxation into account, equilibrium in the tourism market requires

$$
N F_{i}\left(k_{i}\right)=Z\left(p_{D}\right) \equiv Z\left(p_{S}+\tau\right)
$$

Finally, inserting the government's budget constraint (12) into the agent's flow budget constraint (1a') gives the decentralized economy's current account

$$
\dot{b}_{i}=p_{D} F_{i}\left(k_{i}\right)-x_{i}-C\left(I_{i}\right)+r b_{i}
$$




\section{Decentralized macroeconomic equilibrium}

As in the centrally planned economy, we get the short-run solutions

$$
\begin{gathered}
x_{i}=x(\bar{\lambda}), \quad \frac{d x}{d \bar{\lambda}}=\frac{1}{U_{i}^{\prime \prime}}<0 \\
I_{i}=I(q), \quad \frac{d I}{d q}=\frac{1}{C^{\prime \prime}}>0 \\
p_{D}=p_{D}\left(k_{i}\right), p_{D}^{\prime}=\frac{N F_{i}^{\prime}}{Z^{\prime}}<0, \quad p_{S}=p_{S}\left(k_{i}, \tau\right), \frac{\partial p_{S}}{\partial k_{i}} \equiv p_{S k_{i}}=p_{D}^{\prime}
\end{gathered}
$$

where now goods market clearance determines the demand price $p_{D}$, from which it easily follows the supply price $p_{S}=p_{D}-\tau$.

Applying the same method as in the centrally planned economy, the linearized internal dynamics in the decentralized economy become

$$
\left(\begin{array}{c}
\dot{k}_{i} \\
\dot{q}
\end{array}\right)=\left(\begin{array}{cc}
0 & 1 / C^{\prime \prime} \\
-\left[p_{S k_{i}} F_{i}^{\prime}+\tilde{p}_{S} F_{i}^{\prime \prime}\right] & r
\end{array}\right)\left(\begin{array}{c}
k_{i}-\tilde{k}_{i} \\
q-\tilde{q}
\end{array}\right),
$$

The characteristic equation is now

$$
\varphi(\mu)=\mu^{2}-r \mu+\frac{1}{C^{\prime \prime}}\left[p_{S k_{i}} F_{i}^{\prime}+\tilde{p}_{S} F_{i}^{\prime \prime}\right]=0
$$

Again, the two eigenvalues have different signs, $\mu_{1}<0$ and $\mu_{2}>0$, and the stable internal and external dynamics evolve according to

$$
\begin{gathered}
k_{i}(t)-\tilde{k}_{i}=\left(k_{i 0}-\tilde{k}_{i}\right) e^{\mu_{1} t} \\
q(t)-\tilde{q}=\mu_{1} C^{\prime \prime}\left(k_{i 0}-\tilde{k}_{i}\right) e^{\mu_{1} t} . \\
b_{i}(t)-\tilde{b}_{i}=\frac{\Omega_{1}}{\mu_{1}-r}\left(k_{i}(t)-\tilde{k}_{i}\right)
\end{gathered}
$$

where $\Omega_{1} \equiv p_{D}^{\prime} \tilde{F}_{i}+\tilde{p}_{D} F_{i}^{\prime}-\mu_{1}$. Assuming again price elastic demand, $\Omega_{1}>0$. Hence, the dynamics are qualitatively the same as in the centrally planned economy. However, as in general $\mu_{1}^{*} \neq \mu_{1}$, the speed of adjustment is not the same. Thus, the centralized and the decentralized economies grow at different rates towards their steady states. 


\section{Steady state in the decentralized economy}

The steady state in the decentralized economy is determined by the set of equations

$$
\begin{aligned}
& U_{i}^{\prime}\left(\tilde{x}_{i}\right)=\bar{\lambda} \\
& \tilde{q}=1 ; \quad \tilde{I}_{i}=0 \\
& N F_{i}\left(\tilde{k}_{i}\right)=Z\left(\tilde{p}_{S}+\tau\right) \\
& \tilde{p}_{S} F_{i}^{\prime}\left(\tilde{k}_{i}\right)=r \\
& \left(\tilde{p}_{S}+\tau\right) F_{i}\left(\tilde{k}_{i}\right)-\tilde{x}_{i}+r \tilde{b}_{i}=0 \\
& b_{i 0}-\tilde{b}_{i}=\frac{\Omega_{1}}{\mu_{1}-r}\left(k_{i 0}-\tilde{k}_{i}\right)
\end{aligned}
$$

Equations (11a') and (11b') do not require further comment. Equations (11c') and (11d'), jointly determine the supply price $\tilde{p}_{S}$ and the capital stock $\tilde{k}_{i}$. The major difference to the steady state in the centrally planned economy is that the steady-state return on capital consists only of the private dividend yield $\tilde{p}_{S} F_{i}^{\prime}$, as the representative agent ignores the additional positive or negative dividend yield stemming from the externality.

\section{Comparison of steady states}

To compare the steady state of the two regimes, we assume that the government does not intervene into the market by setting the specific tax equal to zero $(\tau=0)$. Hence, $p_{S}=p_{D}=p$. Suppose that the level of tourism production is such that it creates a negative externality, i. e., $V_{i}^{\prime}<0$. Comparing (11d) with (11d'), we see that the steady-state capital stock in the decentralized economy is higher than in the first-best optimum, $\tilde{k}_{i}>\tilde{k}_{i}^{*}{ }^{26}$ In turn, this implies a higher level of tourism service production and a lower relative price, $\tilde{p}<\tilde{p}^{*}$ than socially optimal. Thus, the market price does not reflect the true social cost of tourism production. If the externality is a positive one, i. e., $V_{i}^{\prime}>0$, these results simply reverse, as the market price is to high and does not reflect the social benefit associated with tourism service production. Starting off from the same initial values of capital and traded bonds, in general the consumption levels will be different, as both the value of tourism production in terms of the import 
$\operatorname{good} \tilde{p} \tilde{F}_{i}$ and net interest earnings $r \tilde{b}_{i}$ differ. $^{27}$ However, regardless of which economy allows more consumption, welfare of the representative agent is higher in the centrally planned economy, because the externality is fully internalized.

As in general the first-best optimum achieved in the centrally planned economy and the equilibrium in the decentralized economy are not the same, there is room for the government to implement the first-best optimum by appropriate taxation of tourism services. This is the task of the next section.

\section{Replication of first-best optimum and policy implications}

The equilibrium corresponding to that of the centrally planned economy, derived in section 3 , represents the first-best optimum, as the externality is fully taken into account. We now determine the tourism tax (subsidy) that will enable to replicate the first-best optimum by the decentralized economy. There are two general requirements to be met. The first is that the decentralized economy must ultimately attain the steady state of the centralized economy. Second, having replicated the steady state, the transitional dynamic adjustment paths in the two economies must also coincide. In general, to achieve these two objectives, the optimal tourism tax (subsidy) $\hat{\tau}$ must be time-varying (see Turnovsky (1997)).

We first consider the steady state. In order for the steady state in the two economies to coincide, the capital stock in the two economies and the marginal utility of wealth (and thus the consumption levels) must be equal, i.e., $\tilde{k}_{i}=\tilde{k}_{i}^{*}$ and $\bar{\lambda}=\bar{\lambda}^{*}$. Provided that this equalities are met, tourism service production as well as the demand price $p_{D}$ (via goods market clearance) coincide as well $\left(\tilde{p}_{D}=\tilde{p}^{*}\right) . \tilde{k}_{i}=\tilde{k}_{i}^{*}$ if and only if the rate of return on capital in the two economies, (4d) and (4d'), coincide, i. e.,

$$
\left[\tilde{p}\left(\tilde{k}_{i}^{*}\right)+\frac{V_{i}^{\prime}\left(F_{i}\left(\tilde{k}_{i}^{*}\right)\right)}{\bar{\lambda}^{*}}\right] F_{i}^{\prime}\left(\tilde{k}_{i}^{*}\right)=\left[p_{D}\left(\tilde{k}_{i}^{*}\right)-\hat{\tau}\right] F_{i}^{\prime}\left(\tilde{k}_{i}^{*}\right)
$$

Solving for $\hat{\tau}$, the decentralized steady state will coincide with that in the centralized economy if and only if

$$
\hat{\tau}=-\frac{V_{i}^{\prime}\left(F_{i}\left(\tilde{k}_{i}^{*}\right)\right)}{\bar{\lambda}^{*}}
$$

Thus, the optimal tourism tax reflects the externality facing the economy. It equals the additional positive or negative dividend yield in steady state, caused by the externality, thus equalizing the private and the social steady-state rates of return on capital. In case of a negative (positive) externality, $V_{i}^{\prime}<0\left(V_{i}^{\prime}>0\right)$, 
and tourism services have to be taxed (subsidized) according to (18) to internalize the externality. The reason is simple. In case of a negative externality, tourism demand and hence tourism service production are too high. To reduce demand, a specific tax should be imposed. This in turn increases the demand price $p_{D}$ and reduces the supply price $p_{S}$, and the rate of return on capital falls below the rate of return on bonds (the interest rate), thus agents reduce their steady-state capital stock, and tourism production falls.

Given then production, to replicate the steady-state levels of consumption of the two economies and to ensure that $\bar{\lambda}=\bar{\lambda}^{*}$ (equations (11a) and (11a')), the steady-state levels of bonds have to be equal, see equations (11e) and (11e'). But this last requirement is met if and only if the intertemporal budget constraints of the two economies, (11f) and (11f'), coincide. This in turn requires the stable root of the two systems to coincide, too.

This brings us directly to the second general requirement that the transitional dynamics need to be replicated. In general, if the tourism tax in the decentralized economy is set according to (18) during transition, the adjustment path followed by the decentralized economy will fail to mimic that of the first-best optimum. In appendix A.2 we establish that

$$
\mu_{1}^{*}<\mu_{1}<0
$$

If the tourism tax is fixed over time as in (18), the decentralized economy will converge too slowly relative to the first-best rate of adjustment, as described by (8) and (10). The intuition for this result can be best understood in case of a positive externality $\left(V_{i}^{\prime}>0\right)$. Because agents do not recognize that an increase in the capital stock has an additional benefit via increased tourism, they accumulate capital too slowly. If the externality is negative, starting off from $k_{i 0}$, to reach the relatively lower first-best steady-state capital stock, a higher speed of convergence is socially optimal. ${ }^{28}$

The speed of adjustment can be modified by introducing a time-varying component to the tourism tax, based on the average level $k \equiv K / N$ of the aggregate capital stock $K \equiv N k_{i}^{29}$ :

$$
\tau(t)=\hat{\tau}+\theta\left(k(t)-\tilde{k}^{*}\right)
$$

Obviously, this leaves the tax $\hat{\tau}$ to implement the first-best steady state unchanged. However, it changes 
the average (aggregate) dynamics of the market price of installed capital, equation (4d'), and hence capital accumulation, despite the fact that individual agents do not take the time-varying tax rate into account, as they are to small to influence the economy's average capital stock, on which the tax rate is based. The dynamics of the market price of installed capital becomes

$$
\dot{q}=r q-\left[p_{D}\left(k_{i}\right)-\hat{\tau}-\theta\left(k_{i}(t)-\tilde{k}_{i}^{*}\right)\right] F_{i}^{\prime}\left(k_{i}\right)
$$

The linearized dynamic system (6') of the decentralized economy is then

$$
\left(\begin{array}{c}
\dot{k}_{i} \\
\dot{q}
\end{array}\right)=\left(\begin{array}{cc}
0 & 1 / C^{\prime \prime} \\
-\left[\left(p_{D}^{\prime}-\theta\right) F_{i}^{\prime}+\left(p_{D}\left(\tilde{k}_{i}\right)-\hat{\tau}\right) F_{i}^{\prime \prime}\right] & r
\end{array}\right)\left(\begin{array}{c}
k_{i}-\tilde{k}_{i} \\
q-\tilde{q}
\end{array}\right)
$$

with has the characteristic equation

$$
\chi(\mu)=\mu^{2}-r \mu+\frac{1}{C^{\prime \prime}}\left[\left(p^{\prime}-\theta\right) F_{i}^{\prime}+(\tilde{p}-\hat{\tau}) F_{i}^{\prime \prime}\right]=0
$$

where we note that $p_{D}^{\prime}=p^{\prime}$ and $\tilde{p}_{D}=\tilde{p}=\tilde{p}^{*}$, because $\hat{\tau}$ implies $\tilde{k}_{i}=\tilde{k}_{i}^{*}$. Using the optimal steadystate tax rate (18), the characteristic equation ( 7 ') is equal to the centralized economy's characteristic equation (7) if and only if

$$
\left(p^{\prime}+\frac{V_{i}^{\prime \prime} F_{i}^{\prime}}{\bar{\lambda}}\right) F_{i}^{\prime}+\left(\tilde{p}+\frac{V_{i}^{\prime}}{\bar{\lambda}}\right) F_{i}^{\prime \prime}=\left(p^{\prime}-\theta\right) F_{i}^{\prime}+\left(\tilde{p}+\frac{V_{i}^{\prime}}{\bar{\lambda}^{*}}\right) F_{i}^{\prime \prime}
$$

which requires

$$
\theta=-\frac{V_{i}^{\prime \prime} F_{i}^{\prime}}{\bar{\lambda}^{*}}>0
$$

Hence, the first-best optimum (both its dynamics and the steady state) is achieved if the time-varying tourism tax is set according to

$$
\tau(t)=-\frac{V_{i}^{\prime}\left(F_{i}\left(\tilde{k}_{i}^{*}\right)\right)}{\bar{\lambda}^{*}}-\frac{V_{i}^{\prime \prime}\left(F_{i}\left(\tilde{k}_{i}^{*}\right)\right) F_{i}^{\prime}\left(\tilde{k}_{i}^{*}\right)}{\bar{\lambda}^{*}}\left(k(t)-\tilde{k}^{*}\right)
$$

By setting the tourism tax according to (21), the government is able to induce the decentralized economy to exactly mimic the centrally planned economy by replicating the first-best optimum in the sense that 
both the steady state and the transitional path will be attained.

If the externality is negative $\left(V_{i}^{\prime}<0\right)$, for example because initially tourism production is already quite high, and if the economy is growing, i. e., $k_{i}<\tilde{k}_{i}^{*}$, the optimal tourism tax is positive and increases over time: $0<\tau(t)<\hat{\tau}$. If the externality is positive $\left(V_{i}^{\prime}>0\right)$, say because the economy starts off from a low level of tourism, and $k_{i}<\tilde{k}_{i}^{*}$, the optimal tourism tax turns out to be a subsidy (negative tax rate), becoming smaller over time: $\tau(t)<\hat{\tau}<0$. The intuition why the time-varying tourism tax increases the convergence speed is straightforward. As agents have perfect foresight, they know that the tourism tax (the tourism subsidy) will rise (fall) over time, thus reducing the private dividend yield on capital $p_{S} F_{i}^{\prime} / q$, as a change in the tax rate affects the supply price $p_{S}$. Hence, they will initially take advantage of the relatively low (high) tax (subsidy) rate and increase investment into capital, which speeds up the dynamics.

It is also possible that initially the level of tourism service production and thus the capital stock is such that the "multiple externality" is positive, whereas the economy's steady state is characterized by a level of tourism associated with a negative externality; that is, because of the intersecting nature of the various externalities of tourism, the sign of the overall externality switches during transition. In that case, whereas the taxation rule (21) remains the same, the optimal policy requires a decreasing subsidy rate in the earlier stage of the economy's development, whereas in the later stage an increasing tourism tax is necessary. Hence, the policy has to switch together with the externality. In sum, regardless of the type of externality, in a growing tourism economy the optimal policy for fully internalizing the "multiple externality" requires that the tax rate (subsidy rate) rises (falls) over time.

The model has important and straightforward policy implications: If tourism is associated with negative externalities, as it is likely in the case of mass tourism, it should be taxed; if the externality is positive, as it may be the case for other types of tourism, e. g. "soft ecotourism", tourism should be promoted with a subsidy. Externalities could also be corrected by using regulations and standards. These results are, of course, well known. However, the policy makers' problem is more complex. A lot of negative and positive externalities associated with tourism, as stated in the introduction, are qualitatively obvious. But aggregating them into a multiple externality and assessing its sign and magnitude will be much more tricky, but not impossible. Moreover the evolution and the behavior of the externalities over time deserves policy makers' particular attention. Figuring out the exact pattern and magnitude of the 
(multiple) externality will be a difficult task, requiring a great deal of scientific knowledge and a sophisticated system of information and monitoring. As externalities associated with tourism seem to be very important, as numerous examples suggest, local or regional governments should thus spent sufficient effort in assessing the true state of tourism externalities and what level of tourism would be desirable from a social point of view. Having gathered this information, in practice the externality can then be best corrected by influencing the market price of tourism services via taxation or a subsidy rather than by imposing standards, which are usually an inefficient way tom cope with externalities. Moreover, as long as the externality is negative, a welcome side effect will be the generation of tax revenue. On the other hand, paying subsidies and spending money in case of positive externalities and setting thus adequate incentives seems to be a better way as directly interfere in the managerial decisions of tourism firms, which often results in other inefficiencies. Last but not least, taxes or subsidies can easily and continuously be adjusted, a necessity to handle multiple externalities over time, whereas changes in regulations and standards are often much more difficult to accomplish.

In light of our analysis, the empirical evidence for increasing rates of tourism taxation found by Forsyth and Dwyer (2002) could thus be interpreted as an attempt of governments to correct for negative externalities caused by tourism, whereas in reality the main reason for tourism taxation will be the generation of revenue. However, as externalities caused by tourism seem to be important, increasing tax rates, motivated by fiscal reasons, can be justified on grounds of economic efficiency and can have the desirable side effect of correcting at least partially for negative externalities.

\section{Conclusion}

This paper addresses the policy issue how to correct for "multiple externalities" caused by tourism, using a simple model of a small island economy, completely specialized in the production of tourism services, facing a perfect world capital market on which it can borrow or lend at a given interest rate. Thus, the economy's development is not constrained period by period by tourism earnings. Rather, an intertemporal solvency condition has to be met. The model, simple as it is, delivers thus a realistic first picture of a region in which tourism is the main contributor to the region's income.

It is well documented that tourism may be associated with big externalities, both positive and negative. As the market for tourism services does not recognize these externalities, the laissez-faire market equilib- 
rium is sub-optimal from a social point of view. To improve residents' wellbeing, the government should tax or subsidize tourism, depending on the sign of the overall externality. As our analysis shows, the tax, levied on tourists, should be time-variant, i. e., dynamic. In a growing tourism economy where a negative (positive) externality is present, the tax (subsidy) rate should be rising (falling) over time to implement the first-best optimum a social planner would choose in a centralized economy to maximize welfare. The reason why a time-variant policy instrument is necessary is that is does not suffice to implement the first-best steady state of the centrally planned economy. Due to the fact that economies spend most of their time adjusting to structural changes, it is important to mimic the adjustment speed of the centrally planned economy, too. Only when the economy converges with the socially optimal rate, overall welfare is maximized. A policy switch from a dynamic subsidy to a dynamic tax is necessary if the sign of the "multiple externality" switches during the growth process of the economy.

Due to the fact that in many tourism destinations negative effects caused by tourism are obvious, in such regions taxation of tourism turns out to be a good thing, even if the government introduced taxation not to correct for an externality, but to generate revenue. As tourism is relatively heavily taxed, with tax rates increasing, one can expect that the magnitude of (negative) externalities is at least dampened; in other words: without taxation, the negative side effects would be even larger.

Our model and the results add to the existing literature (e. g., Piga (2003), Pintassilgo and Silva (2007), Candela et al. (2007), Cerina (2007), Gómez et al. (2008)), as the model uses a general equilibrium framework with considers the international financial market too, and as the analysis is not restricted by using particular functional forms. We thus can show that and how the tax rate has to be intertemporally adjusted.

Our model and the results contribute substantially to the existing literature (e.g., Piga (2003), Pintassilgo and Silva (2007), Candela et al. (2007), Cerina (2007), Gómez et al. (2008)), as we apply an intertemporal general equilibrium framework that considers the international financial market too, and as our analysis is not restricted by using particular functional forms. We thus can show that and how the tax rate has to be intertemporally adjusted. Moreover, the model provides a nice justification for increasing rates of tourism taxation, as empirically found by Forsyth and Dwyer (2002).

Of course, the case of a small island economy is an extreme one. Hence, one natural extension of the model would be to add a second sector and a second traded or non-traded good, which may be consumed 
and/or invested, and to consider more explicitly externalities between the economy's sectors and how to handle them. Another possible extension would be to model the tourism industry as an oligopoly with differentiated goods, and analyzing the effects of strategic interaction between different tourism destinations with respect to externalities and how to cope with them.

Finally, we conclude with a caveat. In our model, the "multiple externality" is a simple one, as it can be directly measured in terms of tourism service production, and the dynamic tax policy can be readily derived. In practice, however, externalities are typically hard to identify precisely. Therefore, it is difficult to be sure about the appropriate policy response. This is particularly true in the case of intersecting externalities. To handle them, a highly sophisticated system of information and monitoring is necessary.

\section{A. Appendix}

\section{A.1. Dynamics of bonds $b_{i}(t)$}

The linearized current account is given in equation (9) as

$$
\dot{b}_{i}^{*}-r\left(b_{i}^{*}-\tilde{b}_{i}^{*}\right)=\Omega_{1}^{*}\left(k_{i}^{*}-\tilde{k}_{i}^{*}\right)
$$

Inserting the stable solution for $k_{i}^{*}(t)$, equation (8a), and multiplying with the integrating factor $e^{-r s}$, gives

$$
\frac{d\left[\left(b_{i}^{*}(s)-\tilde{b}_{i}^{*}\right) e^{-r s}\right]}{d s}=\Omega_{1}^{*}\left(k_{i 0}-\tilde{k}_{i}^{*}\right) e^{\left(\mu_{1}^{*}-r\right) s}
$$

Noting that because of the linearization $\Omega_{1}^{*}$ is treated as constant, integrating over $s$ leads next to

$$
\int_{0}^{t} \frac{d\left[\left(b_{i}^{*}(s)-\tilde{b}_{i}^{*}\right) e^{-r s}\right]}{d s} d s=\Omega_{1}^{*}\left(k_{i 0}-\tilde{k}_{i}^{*}\right) \int_{0}^{t} e^{\left(\mu_{1}^{*}-r\right) s} d s
$$

Performing the integration results in

$$
\left[b_{i}^{*}(t)-\tilde{b}_{i}^{*}\right] e^{-r t}-\left[b_{i 0}-\tilde{b}_{i}^{*}\right]=\frac{\Omega_{1}^{*}}{\mu_{1}^{*}-r}\left(k_{i 0}-\tilde{k}_{i}^{*}\right)\left(e^{\left(\mu_{1}^{*}-r\right) t}-1\right)
$$


Rearranging gives then

$$
\begin{aligned}
b_{i}^{*}(t)-\tilde{b}_{i}^{*}= & {\left[\left(b_{i 0}-\tilde{b}_{i}^{*}\right)-\frac{\Omega_{1}^{*}}{\mu_{1}^{*}-r}\left(k_{i 0}-\tilde{k}_{i}^{*}\right)\right] e^{r t} } \\
& +\frac{\Omega_{1}^{*}}{\mu_{1}^{*}-r}\left(k_{i 0}-\tilde{k}_{i}^{*}\right) e^{\mu_{1} t}
\end{aligned}
$$

This is the general solution for $b_{i}^{*}(t)$. Noting that $\beta=r$, the transversality conditions (4e), are satisfied if and only if

$$
\left(b_{i 0}-\tilde{b}_{i}^{*}\right)-\frac{\Omega_{1}^{*}}{\mu_{1}^{*}-r}\left(k_{i 0}-\tilde{k}_{i}^{*}\right)=0
$$

This is the economy's intertemporal budget constraint. Noting that

$$
k_{i}^{*}(t)-\tilde{k}_{i}^{*}=\left(k_{i 0}-\tilde{k}_{i}^{*}\right) e^{\mu_{1} t}
$$

the stable solution for $b_{i}^{*}(t)$ is

$$
b_{i}^{*}(t)-\tilde{b}_{i}^{*}=\frac{\Omega_{1}^{*}}{\mu_{1}^{*}-r}\left(k_{i}^{*}(t)-\tilde{k}_{i}^{*}\right)
$$

which is $(10)$ in the text.

\section{A.2. Proof that $\mu_{1}^{*}<\mu_{1}$}

We show that the stable eigenvalue in the two economies are different. To see this, we consider the internal dynamics of $k$ and $q$. The decentralized economy's characteristic equation (7') when the tourism tax is set $\tau=\hat{\tau}$, thus replicating the steady-state capital stock, tourism production and demand price $p_{D}$ (remember that $\tilde{p}_{D}=\tilde{p}^{*}$ and $p_{S k}=p_{D}^{\prime}=p^{\prime}$, as tourism demand in the two economies is equal), is given as:

$$
\varphi(\mu)=\mu^{2}-r \mu+\frac{1}{C^{\prime \prime}}\left[p^{\prime}\left(\tilde{k}_{i}^{*}\right) F_{i}^{\prime}\left(\tilde{k}_{i}^{*}\right)+\left(\tilde{p}^{*}-\hat{\tau}\right) F_{i}^{\prime \prime}\left(\tilde{k}_{i}^{*}\right)\right]=0
$$

The equilibrium eigenvalue in the decentralized economy is the negative solution to that equation. The equilibrium eigenvalue in the centralized economy is the negative solution to the quadratic equation (7), 


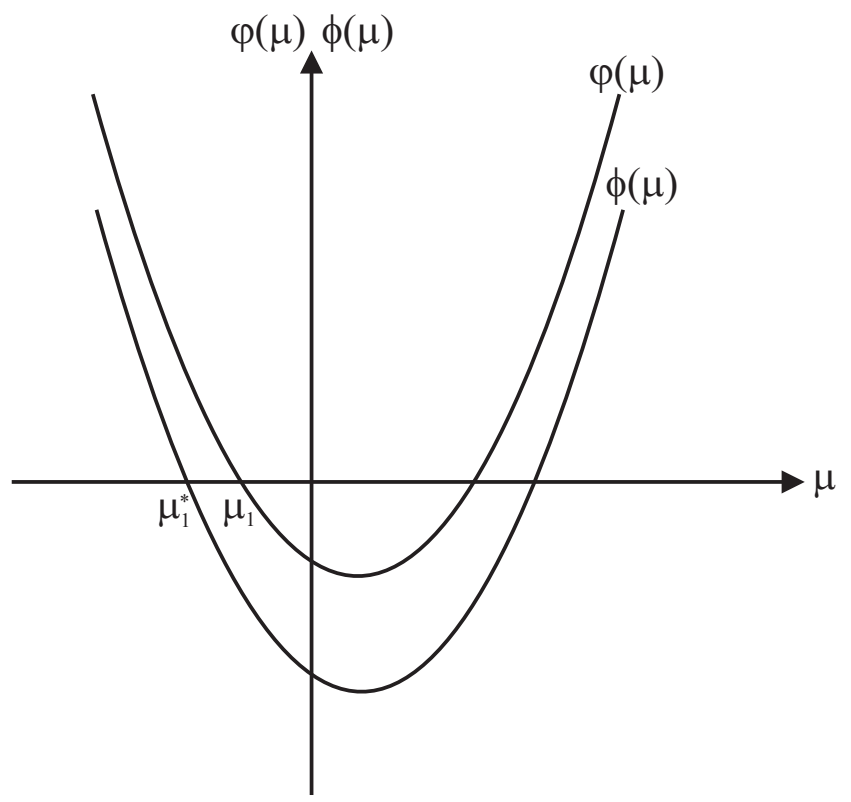

Figure 1: Stable eigenvalue - centralized vs. decentralized economy

repeated here for convenience

$$
\phi\left(\mu^{*}\right)=\left(\mu^{*}\right)^{2}-r \mu^{*}+\frac{1}{C^{\prime \prime}}\left[\left(p^{\prime}+\frac{V_{i}^{\prime \prime} F_{i}^{\prime}}{\bar{\lambda}}\right) F_{i}^{\prime}+\left(\tilde{p}^{*}+\frac{V_{i}^{\prime}}{\bar{\lambda}}\right) F_{i}^{\prime \prime}\right]=0
$$

where the derivatives are calculated at $\tilde{k}_{i}^{*}$ and $F_{i}\left(\tilde{k}_{i}^{*}\right)$. Subtracting (A.5) from (A.4) for a common value of $\mu$, we get

$$
\varphi\left(\mu^{*}\right)-\phi\left(\mu^{*}\right)=\frac{1}{C^{\prime \prime}}\left[p^{\prime} F_{i}^{\prime}+\left(\tilde{p}^{*}-\hat{\tau}\right) F_{i}^{\prime \prime}-\left(p^{\prime}+\frac{V_{i}^{\prime \prime} F_{i}^{\prime}}{\bar{\lambda} *}\right) F_{i}^{\prime}-\frac{r F_{i}^{\prime \prime}}{F_{i}^{\prime}}\right]
$$

Substituting the optimal tax (18) and noting that $V_{i}^{\prime} / \bar{\lambda}^{*}+\tilde{p}^{*}=r / F_{i}^{\prime}>0$, we find that

$$
\varphi\left(\mu^{*}\right)-\phi\left(\mu^{*}\right)=-\frac{1}{C^{\prime \prime}} \frac{V_{i}^{\prime \prime} F_{i}^{\prime}}{\left(\bar{\lambda}^{*}\right)^{2}}>0
$$

Because the functions $\varphi(\mu)$ and $\phi(\mu)$ have a positive quadratic term, it follows that

$$
\mu_{1}^{*}<\mu_{1}<0
$$

This result is illustrated in the figure. 


\section{Notes}

${ }^{1}$ That is, residents can use offers made to tourists, too.

${ }^{2}$ For these and other examples for externalities associated with tourism, see Liu et al. (1987), Palmer and Riera (2003), Cushman et al. (2004), Barros (2006), Pintassilgo and Silva (2007), Candela et al. (2007), Cooper et al. (1998, ch. 7, 8), and others.

${ }^{3}$ For a textbook example of a tax for internalizing an externality in the area of tourism, see Candela and Figini (2003, ch. 15).

${ }^{4}$ See, e. g., Forsyth and Dwyer (2002).

${ }^{5}$ As a general rule, taxation of the tourism industry ultimately means taxation of the tourists, see Forsyth and Dwyer (2002).

${ }^{6}$ Recently there is a growing literature in tourism economics using models which apply dynamic optimization methods, see, e. g., Hazari and Sgro (2004, ch. 12), Chao et al. (2005), Candela and Cellini (2006), Cerina (2007), Faria (2008), Schubert and Brida (2008), and Gómez et al. (2008).

${ }^{7}$ Almost all papers on tourism neglect the possibility of foreign borrowing. One exception is Schubert and Brida (2008).

${ }^{8}$ Models in which capital formation is entirely financed by tourism earnings can be found in papers dealing with the tourismled growth hypothesis, e. g., Hazari and Sgro (2004, ch. 12), and Nowak et al. (2007).

${ }^{9}$ While the concentration on the steady state has its own merits and allows to address important issues in a tractable way, is has also its shortcomings, as empirical evidence suggests that economies spend most of their time adjusting to structural changes.

${ }^{10}$ Whilst the assumption of complete specialization is an extreme one and may be unrealistic in practice, it allows us to develop a simple one-sector model which is analytically tractable. Moreover, in a comprehensive study, Brau et al. (2007) found that for small countries specialization in tourism is beneficial for growth. An econometric study done by Lanza et al. (2003) suggests that growth of real incomes may be supported by specializing in tourism, as the terms of trade shift in favor of the specializing country.

${ }^{11}$ Of course, an island economy may not be populated with a large number of agents. All that matters is that each agent considers itself as being too small as that his decisions have an effect on the market. As it is well known from imperfect competition models, the real market structure can often be approximated by perfect competition even if the number of agents is quite small.

${ }^{12}$ While the assumption of a given interest rate may not be reasonable for some developing countries, it clearly holds for a region within a country, to which the model applies equally well.

${ }^{13}$ There is a lot of empirical evidence that the price elasticity of tourism demand is quite low, but above unity. E. g., Lanza et al. (2003) derived price elasticities in the range between 1.03 and 1.82. See also the comparison of different studies on elasticities in Garín-Muños (2007).

${ }^{14}$ Where no ambiguity can arise we shall adopt the convention of letting primes denote total derivatives and appropriate subscripts partial derivatives. Thus, we shall let $f^{\prime}(x) \equiv \frac{d f}{d x} ; f_{i}\left(x_{1}, \ldots, x_{n}\right) \equiv \frac{\partial f}{\partial x_{i}}, f_{i j} \equiv \frac{\partial^{2} f}{\partial x_{i} \partial x_{j}}$. Time derivatives will be denoted by dots above the variable concerned, $\dot{x} \equiv \frac{d x}{d t}$.

${ }^{15}$ Alternatively and without loss of generality, one could work with the simplifying assumption $N=1$. 
${ }^{16}$ This implies that there exists a level of tourism $\check{Z}$ at which the utility out of tourism is at its maximum.

${ }^{17}$ Thus, the model assumes perfect competition, as there is no product differentiation. Alternatively, one could model the tourism industry as an oligopoly with differentiated products, where tourism firms interact strategically, as, e. g., in the dynamic partial equilibrium models of Candela and Cellini (2006) or Faria (2008). However, models of this type usually assume symmetry, thus in equilibrium all firms charge the same price (see e. g. Tirole (1988, ch. 7). Therefore, depending on the concrete nature of the multiple externality, the results obtained from a model where the tourism market is characterized by product differentiation may be qualitatively the same as ours.

${ }^{18}$ Note that $Z=N F_{i}\left(k_{i}\right)$ and thus $\partial Z / \partial k_{i}=N F_{i}^{\prime}$, and that $V_{i}(Z / N)=V_{i}\left(F_{i}\left(k_{i}\right)\right)$, hence $\partial V_{i} / \partial k_{i}=V_{i}^{\prime} F_{i}^{\prime}$.

${ }^{19}$ Note that $q$ is the ratio of the marginal utility of an additional unit of installed capital, $\gamma$, over the the marginal utility of traded bonds, $\lambda$, which can also be interpreted as the marginal cost of an additional unit of uninstalled capital, because one unit of uninstalled capital trades for one foreign bond.

${ }^{20}$ See, e. g., Brock and Turnovsky (1981), p. 180.

${ }^{21}$ Note that in steady state $\tilde{q}^{*}=1$, hence $V_{i}^{\prime} / \bar{\lambda}^{*}+\tilde{p}^{*}=r / F_{i}^{\prime}>0$, regardless of the sign of the externality. Therefore, the system is saddle-path stable.

${ }^{22}$ The second equality follows from the fact that $p^{\prime} \tilde{F}_{i}^{*}=\left(N F_{i}^{\prime} / Z^{\prime}\right) \tilde{F}_{i}^{*}=\left(N \tilde{F}_{i}^{*} / Z^{\prime}\right) F_{i}^{\prime}=\left(\tilde{Z}^{*} / Z^{\prime}\right) F_{i}^{\prime}$. Hence, $p^{\prime} \tilde{F}_{i}^{*}+\tilde{p}^{*} F_{i}^{\prime}=$ $\left(\left(\tilde{Z}^{*} / Z^{\prime}\right)+\tilde{p}^{*}\right) F_{i}^{\prime}=((1 / \eta)+1) \tilde{p}^{*} F_{i}^{\prime}$.

${ }^{23} \mathrm{We}$ assume that the price elasticity of tourism demand remains constant for the range of changes we shall analyze.

${ }^{24}$ If the government pays a specific subsidy, $\tau<0$.

${ }^{25}$ Assuming lump-sum rebates from the government ensures that the use of government funds does not cause additional distortions. If, e.g., the government would use tax revenues to buy consumption goods or to invest in infrastructure, say, additional externalities on the consumers' and/or producers' side will usually arise. While this is an interesting issue, analyzing the effects of different forms of government expenditure is beyond the scope of this paper.

${ }^{26}$ To see this, note that $\tilde{p}^{*}=p\left(\tilde{k}_{i}^{*}\right)$. Since $d\left[p\left(\tilde{k}_{i}^{*}\right) F_{i}^{\prime}\left(\tilde{k}_{i}^{*}\right)\right] / d \tilde{k}_{i}^{*}<0$, it follows that $\tilde{k}_{i}^{*}<\tilde{k}_{i}$ in case of a negative externality.

${ }^{27}$ Because we reasonably assumed tourism demand to be price-elastic, a higher capital stock and thus higher production (and thus lower price) increases the value of tourism services. However, a higher capital stock implies a lower stock of bonds (see (11f) and (11f'), respectively), reducing thus net interest earnings. Which effect dominates and thus in which steady state consumption is higher is not clear on purely analytical grounds.

${ }^{28}$ To gain more intuition, suppose that the initial capital stock is higher than in steady state, $k_{i 0}>\tilde{k}_{i}$, so that the economy is actually shrinking. In case of a negative externality, the decentralized economy decumulates its capital stock and reduces thus tourism production too slowly compared to the social optimum.

${ }^{29}$ Note that because all agents are identical, the average capital stock equals the capital stock of the representative agent, $k=k_{i}$ 


\section{References}

Aguiló, E., Riera, A., and Rosselló, J. (2005). The short-term price effect of a tourist tax through a dynamic demand model. the case of the balearic islands. Tourism Management, 26:359 - 365 .

Barros, C. P. (2006). Analysing the rate of technical change in the portuguese hotel industry. Tourism Economics, 12(3):325 - 346.

Brau, R., Lanza, A., and Pigliaru, F. (2007). How fast are small tourism countries growing? evidence from the data for 1980 - 2003. Tourism Economics, 13(4):603 - 613.

Brock, W. A. and Turnovsky, S. J. (1981). The analysis of macroeconomic policies in perfect foresight equilibrium. International Economic Review, 22:179-209.

Budowski, G. (1976). Tourism and environmental conservation: Conflict, coexistence, or symbiosis? Environmental Conservation, 3(1):27 - 31.

Candela, G., Castellani, M., and Dieci, R. (2007). Il turismo responsabile: un'opportunità per le destinazioni turistiche e per i turisti. Politica Economica, 23(1):83 - 101.

Candela, G., Castellani, M., and Dieci, R. (2008). Economics of externalities and public policy. International Economic Review, 55:285 - 311.

Candela, G. and Cellini, R. (2006). Investment in tourism market: A dynamic model of differentiated oligopoly. Environmental and Resource Economics, 35:41 - 58.

Candela, G. and Figini, P. (2003). Economia del turismo. McGraw-Hill, Milano.

Cerina, F. (2007). Tourism specialization and environmental sustainability in a dynamic economy. Tourism Economics, 13(4):553 - 582.

Chao, C.-C., Hazari, B. R., Laffargue, J.-P., Sgro, P. M., and Yu, E. S. H. (2005). Tourism, jobs, capital accumulation and the economy: A dynamic analysis. Fondazione Eni Enrico Mattei Working Paper No. 136.2005.

Chao, C.-C., Hazari, B. R., and Sgro, P. M. (2004). Tourism, globalization, social externalities, and domestic welfare. Research in International Business and Finance, 18:141 - 149. 
Cooper, C., Fletcher, J., Gilbert, D., Shepherd, R., and Wanhill, S. (1998). Tourism. Principles and Practice. Addison Wesley Longman Publishing, New York, 2 edition.

Cushman, C. A., Field, B. C., Lass, D. A., and Stevens, T. H. (2004). External costs from increased island visitation: Results from the southern thai islands. Tourism Economics, 10(2):207 - 219.

Faria, J. R. (2008). Demographic and technological growth in the tourism market. Tourism Economics, 14(1):115 - 121.

Figini, P., Castellani, M., and Vici, L. (2007). Estimating tourist externalities on residents: A choice modeling approach to the case of rimini. Fondazione Eni Enrico Mattei Working Paper No. 76.2007.

Forsyth, P. and Dwyer, L. (2002). Market power and the taxation of domestic and international tourism. Tourism Economics, 8(4):377 - 399.

Garín-Muños, T. (2007). German demand for tourism in spain. Tourism Management, 28:12 - 22.

Gómez, C. M., Lozano, J., and Rey-Maquieira, J. (2008). Environmental policy and long-term welfare in a tourism economy. Spanish Economic Review, 10(1):41 - 62.

Gooroochurn, N. and Sinclair, M. T. (2005). Economics of tourism taxation: Evidence from mauritius. Annals of Tourism Research, 32(2):478 - 498.

Hayashi, F. (1982). Tobin's marginal q and average q: A neoclassical interpretation. Econometrica, $50: 213-224$.

Hazari, B. R. and Sgro, P. M. (2004). Tourism, Trade and National Welfare. Contributions to Economic Analysis. Elsevier, Amsterdam.

Lanza, A., Temple, P., and Urga, G. (2003). The implications of tourism specialisation in the long run: An econometric analysis for 13 oecd economies. Tourism Management, 24:315 - 321.

Liu, J. C., Sheldon, P. J., and Var, T. (1987). Resident perception of the environmental impacts of tourism. Annals of Tourism Research, 14:17 - 37.

Nowak, J.-J., Sali, M., and Cortés-Jiménez, I. (2007). Tourism, capital good imports and economic growth: Theory and evidence for spain. Tourism Economics, 13(4):515 - 536. 
Palmer, T. and Riera, A. (2003). Tourism and environmental taxes. with special reference to the "balearic ecotax”. Tourism Management, 24:665 - 674.

Piga, C. A. G. (2003). Pigouvian taxation in tourism. Environmental and Resource Economics, 26:343 -359 .

Pintassilgo, P. and Silva, J. (2007). 'tragedy of the commons' in the tourism accomodation industry. Tourism Economics, 13(2):209 - 224.

Schubert, S. F. and Brida, J. G. (2008). Dynamic effects of subsidizing the tourism sector. Tourism Economics, 14(1):57 - 80.

Sen, P. (1994). Savings, investment, and the current account. In van der Ploeg, F., editor, The Handbook of International Macroeconomics, chapter 15, pages 506-534. Blackwell, Cambridge, Massachusetts.

Tirole, J. (1988). The Theory of Industrial Organization. MIT Press, Cambridge, Mass.

Turnovsky, S. J. (1997). Equilibrium growth in a small economy facing an imperfect world capital market. Review of Development Economics, 1(1):1 - 22.

Turnovsky, S. J. (2000). Methods of Macroeconomic Dynamics. MIT Press, Cambridge, Massachusetts, second edition. 